\title{
EDITORIAL
}

\section{Traumatic brain injury in Latin America and the Caribbean: a call for research}

$\mathrm{T}$ raumatic Brain Injury (TBI) is a critical public health problem affecting more than 10 million people worldwide and is set to surpass many diseases as the leading cause of mortality and morbidity by the year $2020 .{ }^{1}$ The burden of this often neglected injury disproportionately affects low and middle income countries (LMICs) which face not only a higher preponderance of risk factors for TBI but also have less developed health systems to deal with the associated health outcomes. Thus, both the incidence of TBI and the case-fatality from TBI can be high and devastating.

The Latin American and Caribbean region (LAC) consists of a large proportion of LMIC with approximately $36 \%$ of the region's population living below the poverty line. ${ }^{2}$ Studies stemming from LAC regarding the burden of TBI are uncommon; and regional data is limited to estimates derived in the mid-nineties. Data from the 1996 Global Burden of Disease Report ${ }^{3}$ focused on three TBI-related outcomes: intra-cranial injury both short and long term, and fractured skull. These data demonstrate extremely high incidence rates of intracranial injury following road traffic injuries (RTI) and violence (table I). The LAC region was found to have the highest incidence of intracranial injury worldwide secondary to an RTI with an incidence rate of 163 per 100 000; this can be compared to a world average of 106 per 100000 . Similarly the incidence rate due to violence was the highest worldwide at 67 per 100000 compared to a world average of 47 per 100000 (table I).

Table I also shows that males demonstrate a significantly higher rate of TBI-related outcomes than females. RTIs and their sequelae are becoming a significant health problem in LAC; their causes are also the focus of some research in the region. ${ }^{4}$ This region also has the second highest rates for short term intracranial injury as a consequence of violence; and violence is the principal cause of death in Brazil, Columbia, Venezuela, El Salvador and Mexico. ${ }^{5}$ Figure 1 shows the percentage of cases of head injury by cause in LAC; RTIs account for $66 \%$ of all cases, which is slightly higher than the global average of $60 \%$. Violence is responsible for $27 \%$ of TBI-related outcomes in the region, which is considerably higher than the global average of $10 \% .6$

A systematic review of the literature revealed that there is a paucity of TBI data from this region. Efforts to quantify the magnitude of the burden are hampered by inconsistencies in the definition of TBI, in addition to the finding that most minor brain injuries are not medically treated and therefore often not reported. When caused by violence e.g. in war or civil unrest settings, TBI often occurs in the context of multi-trauma and is therefore either underreported or misclassified (with other causes of death). This is particularly relevant in Latin America where such a large proportion of TBI are caused by violence.

Data from individual countries provides additional information on the extent of the burden of TBI in parts of Latin America. The incidence rate for TBI in Sao Paulo, Brazil was found to be 360 per 100000,7 much higher than the overall incidence rate of 200 per 100000 for developed countries. ${ }^{8}$ A study from Salvador City, Brazil which described the characteristics of victims of TBI, revealed that $83 \%$ were male, with the most frequent age group being 21 to 30 years. The most common cause was RTIs (41\%), however violence with or without weapons was the second highest cause $(25 \%)$, closely followed by falls (24\%). ${ }^{9}$ Approximately 1745 Mexicans are hospitalized as a result of TBI every year; males (68\%) and those aged 25-44 years are more likely to be affected..$^{10}$ Trends in causes of TBI follow a similar pattern with RTIs and falls as the leading two causes (43\% and $13 \%$ respectively). ${ }^{10}$

TBI amongst children is of growing concern, especially amongst LMIC. There is a great lack of data 
Table I

INCIDENCE RATES (PER IOO 000) OF TRAUMATIC BRAIN INJURY RELATED OUTCOMES (FRACTURED SKULL, SHORT \& LONG TERM INTRACRANIAL INJURY) BY CAUSE IN THE LATIN AMERICAN AND CARIBBEAN REGION

\begin{tabular}{|c|c|c|c|c|}
\hline \multirow[b]{2}{*}{ Cause } & \multirow[b]{2}{*}{ Injury sustained } & \multicolumn{3}{|c|}{ Incidence rates per 100000} \\
\hline & & Male & Female & Total \\
\hline \multirow[t]{3}{*}{ Road traffic accidents } & Fractured skull & 1.6 & 0.8 & 1.3 \\
\hline & Intracranial injury short term & 231 & 95 & 163 \\
\hline & Intracranial injury long term & 8.6 & 3.8 & 6.2 \\
\hline \multirow[t]{2}{*}{ Falls } & Fractured skull & 2.7 & 1.4 & 2 \\
\hline & Intracranial injury long term & 8.6 & 3.8 & 6.2 \\
\hline Other unintentional injuries & Intracranial injury long term & 9.8 & 4.4 & 7.1 \\
\hline \multirow[t]{3}{*}{ Violence } & Fractured skull & I & 0.2 & 0.6 \\
\hline & Intracranial injury short term & 113.7 & 19.6 & 66.5 \\
\hline & Intracranial injury long term & 5.7 & I & 3.3 \\
\hline War & Intracranial injury long term & 1.8 & 1.3 & 1.5 \\
\hline
\end{tabular}

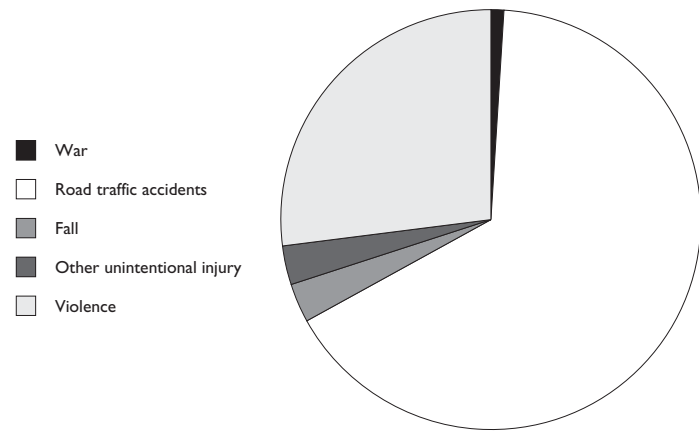

Source: Global Burden of Disease Study ${ }^{3}$

Figure I. Distribution Of HEAD INJURY CASES IN THE LATIN AMERICA REgion, BY CAUSE

surrounding this age group. The causes of TBI amongst children in Latin America are highlighted in a study of 2492 children where $33.5 \%$ were $0-2$ years, $43.8 \%$ between 3-9 years and 22.7\% from 10-15 years. ${ }^{11}$ Falls were found to be the main cause of TBI in children less than three years, and RTIs prevailed as the leading cause of TBI amongst older aged children. An incidence rate of 566 child TBI cases per 100000 and a corresponding mortality rate of 4.65 per 1000 TBI cases was reported; this incidence rate is 2.97 times higher than the international average. ${ }^{11}$

Given that TBI can lead to significant mortality and long term morbidity, not to mention the social and financial implications, the silently growing epidemic of this injury is a pressing public health concern. The lack of data concerning the burden of TBI within LAC should be addressed to develop a detailed epidemiological profile in order to plan comprehensive TBI prevention programs. Prioritizing and coordinating funds for the generation of appropriate evidence and research is critical to meet the need to promote evidence-based policy for TBI in the region.

Prasanthi Puvanachandra, MD, MPH, MA, * Adnan A. Hyder MD, MPH, PhD. ${ }^{\ddagger}$ ahyder@hsph.edu

\footnotetext{
* Post-Doctoral fellow. Department of International Health, Johns Hopkins Bloomberg School of Public Health, USA.

‡ Department of International Health and Center for Injury Research \& Policy, Johns Hopkins Bloomberg School of Public Health, USA.
} 


\section{References}

I. Zitnay GA. Lessons from national and international TBI societies and funds like NBIRTT. Acta Neurochir Suppl 2005;93:131-133.

2. Leipziger D.The unfinished poverty agenda: why Latin America and the caribbean lag behind. Finance and Development 200I;38(I).

3. Murray CJ, López AD. The Global burden of disease: a comprehensive assessment of mortality and disability from diseases, injuries, and risk factors in 1990 and projected in 2020 Boston: Harvard School of Public Health: Harvard University Press, 1996.

4. Hijar-Medina MC, Carrillo-Ordaz CE, Flores-Aldana ME,Anaya R, LópezLópez MV. [Risk factors for injuries caused by traffic accidents and the impact of an intervention on the road]. Rev Saude Publica 1999;33(5): 505-5I2.

5. Briceño-León R.Violence and the right to kill: public perceptions from Latin America.Venezuela: Central University of Venezuela.
6. Gururaj G. An epidemiological approach to prevention - Prehospital care and rehabilitation in neurotrauma. Neurology India 1995;43(3): 95- 105.

7. De Andrade A, Marino R, Ciquini O, Figueiredo E, Machado A. Guidelines for neurosurgical trauma in Brazil. World J Surg 200I;V25(9):I I86-I 201.

8. Bruns J Jr, Hauser WA. The epidemiology of traumatic brain injury: a review. Epilepsia 2003;44(suppl I0):2-10.

9. Melo JR, Silva RA, Moreira ED Jr. Characteristics of patients with head injury at Salvador City (Bahia-Brazil).Arq Neuropsiquiatr 2004;62(3A):7|I-7|4.

10. Brain Injury Association of New Mexico. 2000 [cited 6th December 2006]; Available at: http://www.braininjurynm.org/.

II. Murgio A, Fernández Mila J, Manolio A, Maurel D, Ubeda C. Minor head injury at paediatric age in Argentina.J Neurosurg Sci 1999;43(I):15-23. 